\title{
Futebol para quê? - Arenas da copa como uma estética pós-desenvolmentista
}

\section{RESUMO}

André Luiz Maranhão de Souza Leão

aleao21@hotmail.com

Universidade Federal de Pernambuco, Recife, Pernambuco, Brasil

Bruno Rafael Torres Ferreira brunoferreira@gmail.com Universidade Federal de Pernambuco, Recife, Pernambuco, Brasil

Thiago lanatoni Camargo ianatoni@gmail.com Recife, Pernambuco, Brasil

\section{Bruno Melo Moura}

brunomtop@gmail.com Universidade Federal de $P$ en

\section{Suélen Matozo Franco} suelenmfranco@gmail.com Universidade Federal de Pernambuco, Recife, Pernambuco, Brasil
A construção de novas arenas para a Copa do Mundo 2014 no Brasil suscitou inúmeros questionamentos, sobretudo em relação àquelas apontadas como potenciais "elefantes brancos", como é o caso do Estádio Mané Garrincha (Brasília), da Arena Pantanal (Cuiabá) e da Arena da Amazônia (Manaus). Com base nisto, debruçamo-nos sobre a seguinte questão investigativa: Quais argumentos constituem os discursos acerca das arenas de Manaus, Cuiabá e Brasília? Para esta finalidade, acessamos três posições discursivas (oficial, da sociedade e da mídia), por meio de uma Análise de Discurso Foucaultiana de entrevistas e observação direta, realizadas in loco, bem como de dados documentais. Encontramos na concepção foucaultiana de estética da existência e na Teoria do Pósdesenvolvimento caminhos para a interpretação dos achados, que convergiram para uma formação discursiva que diz respeito a uma lógica de desenvolvimento que busca, antes de um crescimento em si, uma imagem de modernidade compatível com um parâmetro global.

PALAVRAS-CHAVE: Copa do Mundo Fifa 2014; arenas; estética da existência; Teoria do Pós-desenvolvimento; Análise de Discurso Foucaultiana. 


\section{INTRODUÇÃO}

No ano de 2014, o Brasil sediou a Copa do Mundo da Fédération Internationale de Football Association (Fifa). A promessa da entidade e do governo brasileiro era de que a realização da Copa no país traria não só melhorias, mas também um legado positivo (LANGONI, 2013). Para além da insegurança de determinados setores da sociedade com relação a tal promessa (ALMEIDA et al., 2015), um dos aspectos mais criticados com relação às obras realizadas para o evento foi a construção de arenas (vide MARQUES, 2013; GONÇALVES, 2013). Outro aspecto controverso na preparação do evento foi a seleção das cidades-sede. A Fifa e o Governo Federal estavam em desacordo com relação ao número de sedes: enquanto a primeira vislumbrava um número menor, entre oito e dez, este último vislumbrava dezessete; o total de cidades acordado foi de doze, sob a alegação de consonância com a extensão territorial do país e de contemplação de todas as regiões, representando plenamente a identidade nacional (AGÊNCIA ESTADO, 2013).

A opção por contemplar todas as regiões, no entanto, terminou por esbarrar em outro entrave: a seleção de cidades-sede com pouca tradição de futebol, a exemplo de Cuiabá, Manaus e Brasília. Dessa forma, desde a construção de suas respectivas arenas, já se viam tais obras como fortes candidatas a se tornar subutilizadas após o mundial, uma vez que os eventos ligados ao futebol, sozinhos, não seriam suficientes para garantir a sustentabilidade pós-Copa (MENDONÇA, 2015; SEGALLA, 2015; TERRA, 2015). Um estudo realizado pelo Instituto Dinamarquês de Estudos do Esporte já apontava, anos antes da realização do evento, que tais arenas eram candidatas a "elefantes brancos", ou seja, estruturas subutilizadas após o término do evento.

Tal expectativa veio a se confirmar já no ano posterior à Copa, tendo as três totalizado um prejuízo estimado em R\$ 18 milhões (SEGALLA, 2015; TERRA, 2015). Já no início do ano subsequente, o ônus gerado pelos três "elefantes brancos" como foram mencionadas o Estádio Mané Garrincha (Brasília), a Arena Pantanal (Cuiabá) e a Arena da Amazônia (Manaus) - já era estimado em 10 milhões; falase em prejuízo para o contribuinte, tendo em consideração os custos de manutenção das arenas e as respectivas arrecadações: o Estádio Mané Garrincha custou $\mathrm{R} \$ 1,7$ bilhões para ser construído, demanda $\mathrm{R} \$ 600$ mil mensais em manutenção e arrecadou R\$ 5,5 milhões desde 2013; a Arena da Amazônia custou R\$ 669,5 milhões, demanda R\$ 700 mil mensais para manutenção e arrecadou R\$ 1,5 mil desde agosto de 2014; por fim, a Arena Pantanal custou R\$ 628 milhões, demanda R\$300 mil mensais e arrecadou R\$380 mil desde julho de 2014 (MENDONÇA, 2015). A Arena da Amazônia sediou poucos jogos e com baixo público, tendo seu prejuízo atenuado com a realização de shows; a Arena Pantanal realizou o projeto "Vem pra Arena" com programação artística e cultural, no intuito de minimizar as perdas; já o Estádio Mané Garrincha - o mais caro de todos - , recebe alguns jogos e eventos, além de sua área externa servir de estacionamento (TERRA, 2015).

Tendo em vista o elevado investimento realizado pelo Poder Público e a confirmação posterior de que tais investimentos resultariam em prejuízo para os respectivos Estados, aliado à crença de que tais cidades não seriam escolhas adequadas em virtude da pouca tradição de times locais no cenário do futebol nacional, buscamos compreender a pluralidade de vozes e visões envolvidas nos 
discursos acerca da escolha de Brasília, Manaus e Cuiabá como cidades-sede, bem como as respectivas resistências à realização de um evento desse porte nessas cidades. Dessa forma, questionamos: Quais argumentos constituem os discursos acerca das arenas de Manaus, Cuiabá e Brasilia?

A presente investigação justifica-se pela necessidade de compreender como se constituem os discursos acerca do legado do megaevento nas capitais brasileiras, uma vez que os elevados investimentos nas obras das cidades-sedes eram justificados pelo Poder Público como oportunidade de legar uma infraestrutura urbana e esportiva, além de visibilidade e fomento ao turismo. Nesse contexto, merece destaque a construção de arenas, representando não só a aderência a um novo modelo de estádio (SOUTO; TORRES; 2010), como também uma oportunidade de novos negócios envolvendo o futebol (FERNANDES, 2013). Se os legados são justificados pelo Poder Público como uma oportunidade de desenvolvimento, há, por outro lado, a descrença desse conceito de legado, sendo considerado um argumento para se justificar investimentos elevados, ao mesmo tempo que ocultam os impactos negativos das transformações nas populações locais (BELMIRO; CARVALHO, 2014). Esse contexto nos remete à ideia de um enfrentamento entre noções de desenvolvimento distintas, o que, por sua vez, evidencia a possibilidade de se questionar como se estabelecem os discursos que alicerçam tais pensamentos e como estes se articulam, negociando e estabelecendo uma condição de verdade que conduza tanto decisões políticas como comportamentos sociais sob tais conduções de forma naturalizada. Segundo Foucault, a verdade se constitui discursivamente, sob certas condições contingentes e históricas, em meio a um jogo de possibilidades entre diferentes saberes (FOUCAULT, 2014a; 2010a; 2010b).

De forma a não direcionar o estudo, optamos por iniciar a análise dos dados apenas com base numa orientação epistemológica definida - alinhada a uma perspectiva pós-estruturalista, em consonância à escolha da Análise de Discurso Foucaultiana como método, como se discutirá à frente - , mas sem categorias teóricas preestabelecidas, atribuindo ao estudo um caráter indutivo. Apenas após uma primeira rodada de análise, quando identificamos uma estética implícita a uma concepção de desenvolvimento e modernização, definimos uma lente teórica que contribuísse com a continuidade do processo. Nesse sentido, encontramos na concepção foucaultiana de estética da existência e na Teoria do Pós-desenvolvimento planos para a interpretação dos achados.

\section{FUNDAMENTAÇÃO TEÓRICA}

Conforme antecipado, nossa fundamentação teórica se baseia tanto na Teoria do Pós-desenvolvimento, que contempla contribuições do pensamento foucaultiano e da abordagem pós-colonialista, como na concepção de estética da existência, abordada no terceiro ciclo da trajetória de Foucault. A seguir, apresentamos os principais pressupostos dessas abordagens.

\section{Pós-desenvolvimento}

Na matriz pós-estruturalista da Antropologia do Desenvolvimento, temos a Teoria do Pós-desenvolvimento, de perspectiva pós-colonialista e influência do 
pensamento foucaultiano. Seus pressupostos advêm de um debate crítico em torno de diversas perspectivas das ciências sociais sobre desenvolvimento planejado (RADOMSKY, 2011). Entre as décadas de 1980 e 1990, a abordagem se consolida, sobretudo pela contribuição de autores como Esteva (1987), Sachs (1992), Escobar (1995) e Bawtree e Rahnema (1997). Além desses estudos, contribuíram para essa consolidação os trabalhos de Fergunson (1990), Latouche (1993) e Rist (1997). Comunidades indígenas e movimentos sociais de localidades consideradas subdesenvolvidas foram objeto de estudo de diversos pesquisadores do pós-desenvolvimento, tais como a investigação de Arturo Escobar na Colômbia; Gustavo Esteva no México e James Fergunson em Lesoto.

A abordagem pós-desenvolvimentista lança um olhar crítico a um modelo de desenvolvimento planejado na segunda metade do século XX no Ocidente, sob uma perspectiva eurocêntrica e homogeneizante (RADOMSKY, 2011; DINERSTEIN; DENEULIN, 2012). Tal lógica pressupõe a expertise dos países ocidentais considerados desenvolvidos como um modelo para conduzir o desenvolvimento dos países "subdesenvolvidos" ou "do Sul" (Justen; MoretTo Neto, 2013); estes últimos agiriam, portanto, sob a orientação dos primeiros, mediada por agências e organismos internacionais (BRUNO; GUERRINI, 2011; POGODDA, 2014). Haveria, por consequência, uma imposição da cultura eurocêntrica sob o discurso da modernidade a estas localidades, em forma de mercadorias e tecnologias transmitidos de forma verticalizada aos países ditos subdesenvolvidos, desconsiderando-se a cultura local (EsCOBAR, 1995).

Nesse sentido, a Teoria do Pós-desenvolvimento se propõe à desconstrução dos modelos universalizantes de desenvolvimento implícitos nesse processo, bem como as formas de poder que os constituem, baseadas no utilitarismo e na crença de que o crescimento econômico dá-se do ponto de vista mercadológico (LATOUCHE, 2014; Escobar, 2010).

O papel do Estado, enquanto planejador do desenvolvimento, também é alvo de discussão nessa abordagem: questiona-se não só esse papel, como também os interesses personalistas e a desconsideração de demandas sociais que orientam suas práticas (RADOMSKY, 2013; JUSTEN; MORETTO NETO, 2013). Já do ponto de vista micro, considera-se que o planejamento desenvolvimentista pressupõe normas uniformizantes que sujeitam os indivíduos. A coletividade é o pretexto pelo qual essa sujeição se dá, adotando-se modelos restritivos e excludentes (ESCOBAR, 1995; 2010). Isso resulta no esmagamento da diversidade, comprometendo, como consequência, o sujeito da sua autonomia (ESCOBAR, 1995).

Dessa forma, para os teóricos dessa abordagem, o modelo de desenvolvimento é alvo de crítica por ter a violência inerente à sua estrutura, excluindo formas tradicionais de conhecimento, manipulando culturas locais conforme interesses vigentes e destruindo o meio ambiente (DASKON; MCGREGOR, 2012; POGODDA, 2014). Além de apontar essa crítica, buscam indicar propostas de novos modelos de desenvolvimento, que respeitem particularidades locais e enfoquem aspectos humanos (ESCOBAR, 1995).

Nesse contexto, merece destaque o pensamento de Arturo Escobar, uma vez que uma visão de modernidade é rediscutida em sua obra, assim como são discutidas particularidades da América Latina. O Colombiano, focou seu primeiro estudo na realidade de sua terra natal (ESCOBAR, 1995), estendendo suas 
observações posteriormente à Bolívia, à Venezuela e ao Equador (EsCOBAR, 2010). $O$ pensamento foucaultiano foi uma importante influência em sua obra, com destaque para questões como a dinâmica discursiva e a questão do poder. Além dele, autores pós-colonialistas, como Edward Said, Valentin-Yves Mdimbe, Chandra Mohanty e Homi BhaBha, exerceram grande influência ao denunciar o discurso ocidental imposto a diversas localidades. Para Escobar, cabe questionar até mesmo a noção de "Terceiro Mundo", uma vez que é articulada no interior de um discurso daqueles que desejam promover o desenvolvimento. Sob essa premissa, o desenvolvimento seria uma necessidade, que colonizaria a realidade (ESCOBAR, 1995).

A Teoria do Pós-desenvolvimento também é alvo de críticas (e.g. PIETERSE, 2000; ANDREWS; BAWA, 2014). Dentre os aspectos questionados, merece destaque à abordagem das comunidades e tradições locais, considerada romantizada (HORNER, 2013); isso resulta numa visão polarizada, na qual há uma rejeição à modernização, resultando numa postura prescritiva de antidesenvolvimento (KIPPLER, 2010). No entanto, cumpre ressaltar que o propósito da abordagem não é o fim do desenvolvimento (LUMMIS, 1994; PIETERSE, 2000), mas a defesa de um desenvolvimento que valorize a autonomia e respeite as identidades locais, dos pontos de vista cultural, econômico e ambiental (EsCOBAR, 1995). Dessa forma, reivindica a substituição de uma lógica europeia e universalizante de progresso por uma concepção que contemple distintas possibilidades, as alternativas de modernidade, ou alternativas de desenvolvimento (ESCOBAR, 1995; 2010). Essas alternativas pressupõem não só a ruptura de um paradigma de desenvolvimento, mas uma pluralidade de modernidades, ancoradas nas epistemes e realidades locais, constituindo-se em alternativas que proporcionem a proteção e dignidade às vidas no planeta (ESCOBAR, 2010).

\section{Estética da existência}

A centralidade da subjetividade caracteriza o terceiro ciclo do pensamento foucaultiano, quando desvia da investigação das condições de emergência das relações de poder para um novo entendimento do ser. Nesse sentido, este ciclo se caracteriza pela compreensão da possibilidade de o homem subjetivar-se, assumindo que esse processo se dá sob condições de liberdade que possibilitam a ele tornar-se sujeito (GALVÃo, 2014).

O dispositivo da sexualidade na Grécia antiga é o meio pelo qual o filósofo investiga a constituição da sexualidade, do desejo e dos prazeres enquanto objeto de elaboração moral, cuja preocupação por vezes excede a atenção concedida a outros objetos em determinados períodos e sociedades. A regulação das práticas culturais dava-se sob dois eixos: a concessão do direito de os homens administrarem a vida permitindo-se desfrutar os prazeres da sexualidade e, simultaneamente, o enquadramento num regime moral, cuja orientação era agir adequadamente consigo e com os demais. Orientados sob tais regras, os homens possuíam um espaço para decidir sobre como agir (HUIJER, 1999).

No segundo volume de sua obra História da Sexualidade, Foucault (2014b) aborda como o discurso da sexualidade propicia a constituição de valor moral; essa constituição dar-se-ia com base em saberes distintos, tais como o médico e o filosófico, ancorados em quatro estratégias: o medo, que se baseava na 
concepção de finitude da vida e, sob essa perspectiva orientava práticas discursivas normatizadoras de práticas sexuais; um esquema de comportamento que evidenciava condutas sociais e conjugais; tais condutas, por sua vez, contribuíam para que se buscasse uma imagem social respeitável; e, por fim, um modelo de abstenção, na medida em que se exigia do homem o domínio sobre si, necessário para que este possuísse controle sobre a verdade. Com isso, o filósofo não buscava apresentar um modelo universal de dispositivos institucionalizantes, mas tão somente discutir a maneira como uma normatização incide no processo de subjetivação. Para Foucault (2014b), o sujeito constrói sua verdade entre sua vontade, guiada por práticas morais, e a verdade institucionalizada, orientadora da conduta social.

A concepção de sujeito, em Foucault, não pressupõe o controle de uma prática livre e autônoma (GALVÃo, 2014; REVEL, 2005), mas a existência de limites para a que o indivíduo exercite práticas de sujeição, refletidas e voluntárias, que, se por um lado restringem-no ao normatizar condutas, por outro transformamno e permitem-no demarcar sua singularidade. Foucault (2014b) chama tais práticas de práticas de existência (FOUCAULT, 2014b). Estas, por sua vez, são articuladas a uma concepção de estética, enquanto uma busca de forma e sentido, pela busca da produção de um ser sob uma concepção do belo, da vida como uma obra de arte, numa espécie de arte da existência (FOUCAULT, 2010; 2014b).

Assim, a ideia de como o ser humano problematiza o seu existir e o seu mundo corresponde à noção de estética da existência: um modo pelo qual o indivíduo sujeita, sob um conjunto de normas que definem o ser e a maneira de compreendê-lo como tal (FOUCAULT, 2010; 2014b).

Essa estética da existência requer um conjunto de saberes que se relacionam e esteiam a constituição de um ser e o modo como pensá-lo, guiando práticas de existência que não só materializam como permitem essa formação (FOUCAULT, 2014b). No entanto, essa constituição pressupõe um exercício de resistência, compreendendo a sujeição, mas, ao mesmo tempo, uma vigilância permanente ao que é externo (FOUCAULT, 2014b).

Trata-se, portanto, de um exercício de poder de si para consigo, visando à manutenção de sua constituição, com base num conjunto de regras que estabelece o ser para si próprio, o que implica uma ética do sujeito (GALVÃo, 2014: REVEL, 2005). Tais regras, por sua vez, inserem-se num espaço entre uma condição social, a ética e a moral. Dessa forma, a busca por uma estética da vida compreende uma preocupação consigo, com o uso dos prazeres, e com a alteridade, na medida em que busca uma imagem moral em sua relação com o outro (FOUCAULT, 2010).

Um aspecto fundamental para a compreensão da ética do sujeito é a concepção foucaultiana de governo, enquanto um agir sobre a ação, que pode incidir tanto sobre si quanto sobre outros sujeitos. Sob essa perspectiva, analisar o governo compreende o entendimento de como os indivíduos são levados a exercerem uma conduta sobre si e sobre os outros (FOUCAULT, 2014b). Ou seja, cuidar de si e cuidar dos outros são práticas intimamente relacionadas, e um bom governo de si implica um bom governo dos outros (REVEL, 2005). em um jogo de poder (FOUCAULT, 2014b). Para além do exercício da resistência a 
um governo de si ou dos outros, a arte da existência revela-se como uma posição, na qual o sujeito se constitui como tal, é produzida, modificada e diferenciada por meio de práticas ancoradas em regimes de saberes (GALVÃO, 2014).

Diversos estudos críticos sobre subjetividade têm-se valido da abordagemda estética da existência, tais como trabalhos que refletem sobre mulheres com medidas acima dos padrões vigentes (MURRAY, 2008), sobre o corpo como um lugar de resistência a esses padrões (MISKOLCI, 2006); sobre a constituição dos sujeitos homoafetivos (DEAN, 2010; KINGSTON, 2009); sobre a juventude e a estética pós-modernas (FERREIRA, 2016); ou mesmo sobre alternativas à ética vigente nos negócios (CUMMINGS, 2000).

No presente estudo, podemos utilizar o conceito de estética de existência para compreender como um modelo de desenvolvimento imposto pelas nações ocidentais desenvolvidas às regiões consideradas menos desenvolvidas pode ser legitimado ou mesmo perseguido por estas últimas, na medida em que uma rede de saberes estabelece o desenvolvimento como um processo homogêneo e universal, em detrimento de singularidades locais.

\section{PROCEDIMENTOS METODOLÓGICOS}

A presente pesquisa é qualitativa e de perspectiva pós-estruturalista. A investigação tem caráter indutivo, na medida em que apenas uma lente epistemológica foi definida a priori, tendo sido as definições teóricas tomadas a partir do procedimento analítico (LEÃO et al., 2009), conforme explanado na introdução do trabalho.

Como trilha metodológica, adotamos a Análise de Discurso Foucaultiana, baseada em seu ciclo arqueológico, a qual investiga as condições de possibilidade de determinados saberes (FOUCAULT, 2014a). Essa abordagem consiste em compreender a constituição de formações discursivas, que partem de enunciados e suas funções e se baseiam em certas regras. Assim, formações discursivas correspondem a agrupamentos de enunciados com suas respectivas funções e regras de formação. A partir dessa concepção, apresentamos tais categorias analíticas, utilizadas em nossa investigação (vide FoucAULT, 2014a):

- Enunciados: são funções de existência dos signos, que, contudo, excedem o meramente estrutural, referindo-se a temas concretos delimitados espaçotemporalmente; assim, os enunciados não se encontram em conjuntos particulares de signos, tampouco são encontrados de formas isoladas, uma vez que geralmente se inter-relacionam.

-Funções enunciativas: remetem ao modo pelo qual o enunciado "atua"; referem-se a materialidades, apresentando diversas possibilidades de uso e produzindo a própria diferença dos discursos, o que é possível por advirem das vozes de diversas posições de subjetividade na enunciação.

- Regras de formação: as formações discursivas obedecem a certas regras, que dizem respeito aos lugares, às delimitações e às especificações dos enunciados; ao modo pelo qual os sujeitos, a partir das respectivas posições, proferem enunciados; a como se atribuem significados a certas noções num campo enunciativo; e a ideias, temas e teorias que guiam os discursos e discursos e suas respectivas funções num campo não discursivo. 
Foucault (2014a) denomina arquivo o acervo de dados utilizados para a sua análise de discurso, que constitui um conjunto de práticas discursivas que propicia o surgimento de enunciados. No presente estudo, esse conjunto foi constituído por entrevistas, observação direta e documentos, organizados conforme três posições discursivas: a oficial, relativa aos agentes ligados à organização do evento; a da sociedade, relativa à população e aos órgãos de fiscalização; e a da mídia, relativa à imprensa, em relação à cobertura do evento.

$\mathrm{O}$ arquivo foi composto de 79 documentos coletados na Internet - como posts de blogs, matérias jornalísticas, entrevistas, vídeos, fotos e infográficos - e representativos das três posições discursivas mencionadas e do objeto de estudo dessa pesquisa e publicados entre janeiro de 2010 e junho de 2015. Além disso, o acervo contou com observaçõesin loco dascidades-sede, durante viagens realizadas entre janeiro de 2014 e abril de 2016, oportunidade em que foram feitas seis entrevistas em profundidade com jornalistas e 15 entrevistas etnográficas com moradores.Adotamos critérios de representatividade e saturação para a composição deste corpus (BAUER; AARTS, 2005). Por dificuldade de acesso e limitações de agendas nos períodos das viagens, que precisaram ser planejadas com antecedência em virtude da restrição de recursos da pesquisa, não conseguimos entrevistar gestores públicos. Entendemos que o texto jornalístico, cujo princípio técnico pressupõe a pluralidade de vozes, ao integrar nosso arquivo, contemple esses sujeitos.

Seguindo o processo apresentado, a análise do arquivo começou pela identificação dos enunciados, bem como das possíveis relações entre eles. Tais relações foram denominadas síncronas, quando dois enunciados se explicam mutuamente, e incidentes, quando um enunciado explica o outro. Esse processo, por sua vez, orientou-nos à identificação das respectivas funções enunciativas, ressaltando que, por vezes, uma mesma função poderia remeter a mais de um enunciado, assim como um enunciado poderia ter mais de uma função, o que valeu também para a identificação das regras de formação. A partir dos feixes de relações entre enunciados, funções e regras, inferimos a formação discursiva.

Além disso, utilizamos, como critérios de qualidade da pesquisa qualitativa (PAIVA JR. et al., 2011): a triangulação na análise dos dados, que foi originalmente realizada por uma dupla de pesquisadores e em seguida validada por outra dupla, incluindo o coordenador do projeto; a reflexibilidade, por meio de uma avaliação permanente da interpretação dos dados, sobretudo com relação às evidências empíricas e as questões teóricas adotadas; a construção do corpus de pesquisa, na forma do arquivo apresentado, que buscou a necessária representatividade do fenômeno investigado; e, por fim, apresentar uma descrição rica e detalhada da investigação, ainda que, para efeito da elaboração do presente trabalho, dentro da limitação de tamanho definida.

\section{DESCRIÇÃO DOS RESULTADOS}

A partir da análise realizada, identificamos uma formação discursiva decorrente de relações compostas por três regras de formação, cinco funções enunciativas e dezessete enunciados. Passamos a apresentar tais elementos constitutivos dessa formação, identificada e discutida a partir da discussão dos 
feixes de relações que a sustenta, amparada por dados empíricos extraídos do arquivo de pesquisa.

\section{Elementos que constituem a formação discursiva}

Dispomos os enunciados identificados no Quadro 1. De modo a explicitar seus contextos de significação no arquivo, optamos por apresentá-los por meio de proposições afirmativas. Dos 17 enunciados, 3 foram evidenciados nas práticas relativas às três posições discursivas; 11 foram localizadas na posição discursiva da mídia combinada com outra, sendo $10 \mathrm{com}$ a posição discursiva da sociedade e $1 \mathrm{com}$ a oficial; e, por fim, 3 foram identificados apenas nas práticas da imprensa. 


\section{Quadro 1 - Enunciados}

\begin{tabular}{|c|c|c|}
\hline & Enunciados & Descrições \\
\hline \multicolumn{3}{|r|}{ Encontrados nas três posições discursivas } \\
\hline E04 & $\begin{array}{l}\text { A arena é motivo de } \\
\text { orgulho }\end{array}$ & $\begin{array}{l}\text { Remete à ufania da população das cidades-sede pela construção de } \\
\text { um estádio de padrão internacional. Isso é demonstrado pelo } \\
\text { encantamento das pessoas diante de um projeto de caráter global. }\end{array}$ \\
\hline E05 & $\begin{array}{l}\text { A cidade é capaz de atrair } \\
\text { eventos culturais e } \\
\text { esportivos de grande } \\
\text { porte }\end{array}$ & $\begin{array}{l}\text { Refere-se ao potencial das cidades em sediar grandes eventos, o que } \\
\text { passa a ser viabilizado pela construção das arenas. Isso se revela em } \\
\text { argumentos que indicam uma expectativa de as cidades receberem } \\
\text { atrações nacionais e internacionais, bem como visitantes de outras } \\
\text { localidades, domésticas e estrangeiras. }\end{array}$ \\
\hline E09 & $\begin{array}{l}\text { A Copa do Mundo atraiu } \\
\text { uma grande quantidade } \\
\text { de turistas para a cidade }\end{array}$ & $\begin{array}{l}\text { Refere-se a como a realização de jogos da Copa nas cidades } \\
\text { promoveu o turismo durante o evento, sobretudo de estrangeiros. } \\
\text { Isso fica evidente nos relatos que destacam o número de turistas, } \\
\text { principalmente internacionais, que desembarcaram nas cidades } \\
\text { durante o mundial. }\end{array}$ \\
\hline \multicolumn{3}{|c|}{ Encontrados nas posições discursivas oficial e da imprensa } \\
\hline E07 & $\begin{array}{l}\text { A Copa do Mundo } \\
\text { possibilitou } \\
\text { desenvolvimento à } \\
\text { cidade e à população } \\
\text { local }\end{array}$ & $\begin{array}{l}\text { Refere-se a como a adequação à Copa do Mundo proporcionou } \\
\text { melhorias à cidade e às pessoas. Isso se baseia nas obras de } \\
\text { infraestrutura realizadas nas cidades e na capacitação da população } \\
\text { para se adequarem ao padrão do evento. }\end{array}$ \\
\hline \multicolumn{3}{|c|}{ Encontrados nas posições discursivas da sociedade e da imprensa } \\
\hline E01 & $\begin{array}{l}\text { A nova arena muda a } \\
\text { maneira de fruir os jogos }\end{array}$ & $\begin{array}{l}\text { Refere-se como o novo modelo de estádio requer um novo padrão de } \\
\text { comportamento para os que vão aos jogos. Isso é evidenciado com } \\
\text { base na definição de regras e normas a serem seguidas nas arenas, } \\
\text { bem como ao encantamento do público nas novas instalações. }\end{array}$ \\
\hline E06 & $\begin{array}{l}\text { A arena coloca a cidade } \\
\text { no mapa nacional do } \\
\text { futebol }\end{array}$ & $\begin{array}{l}\text { Pronuncia que a construção das arenas insere as cidades-sede no } \\
\text { cenário do futebol brasileiro. Isso é encontrado em argumentos que } \\
\text { valorizam a realização de jogos de clubes de expressão nacional nos } \\
\text { novos estádios, bem como revelam a expectativa de desenvolvimento } \\
\text { dos clubes locais para se adequarem à nova estrutura. }\end{array}$ \\
\hline E08 & $\begin{array}{l}\text { A cidade obteve maior } \\
\text { visibilidade ao sediar a } \\
\text { Copa do Mundo }\end{array}$ & $\begin{array}{l}\text { Refere-se a uma projeção das cidades nos âmbitos nacional e } \\
\text { internacional proporcionada pelo mundial. Isso é evidenciado com } \\
\text { base no reconhecimento de que a Copa propiciou uma maior } \\
\text { presença das cidades na mídia brasileira e estrangeira. }\end{array}$ \\
\hline E11 & $\begin{array}{l}\text { A Copa na cidade foi um } \\
\text { mise en scène }\end{array}$ & $\begin{array}{l}\text { Aponta que as cidades foram "maquiadas" para que parecessem } \\
\text { aptas a receber o evento. Isso é descrito pelo argumento de que as } \\
\text { áreas reservadas à circulação de turistas receberam melhorias } \\
\text { paliativas. }\end{array}$ \\
\hline E12 & $\begin{array}{l}\text { As empresas locais } \\
\text { deveriam patrocinar as } \\
\text { equipes da cidade }\end{array}$ & $\begin{array}{l}\text { Refere-se à concepção de que o futebol das cidades-sede deveria ser } \\
\text { compatível com suas economias. Isso é evidenciado por argumentos } \\
\text { que defendem que as empresas instaladas nessas localidades } \\
\text { deveriam contribuir para o desenvolvimento do futebol local. }\end{array}$ \\
\hline
\end{tabular}




\begin{tabular}{|c|c|c|}
\hline E13 & $\begin{array}{l}\text { Outra cidade da região } \\
\text { seria mais adequada para } \\
\text { sediar a Copa }\end{array}$ & $\begin{array}{l}\text { Aponta uma melhor adequação de outras cidades das regiões para } \\
\text { sediar a Copa do Mundo. Isso é evidenciado em argumentos que } \\
\text { indicam Belém e Goiânia como detentoras de melhores condições } \\
\text { estruturais, localização geográfica e cultura futebolística. }\end{array}$ \\
\hline E14 & $\begin{array}{l}\text { A cidade não comporta } \\
\text { uma arena de padrão } \\
\text { internacional }\end{array}$ & $\begin{array}{l}\text { Profere acerca da ausência de uma estrutura adequada das cidades } \\
\text { para receber uma arena que comporte jogos da Copa do Mundo, bem } \\
\text { como outros eventos internacionais. Isso é evidenciado pelos } \\
\text { depoimentos que relatam a infraestrutura precária das cidades para } \\
\text { receber turistas. }\end{array}$ \\
\hline E15 & A arena é subutilizada & $\begin{array}{l}\text { Refere-se à falta de perspectiva de um uso satisfatório dos novos } \\
\text { estádios. Isso é evidenciado pela descrença de que as cidades sejam } \\
\text { capazes de atrair eventos compatíveis com o porte das arenas. }\end{array}$ \\
\hline E16 & $\begin{array}{l}\text { A arena depende de } \\
\text { times de fora }\end{array}$ & $\begin{array}{l}\text { Indica que as arenas necessitam de jogos de clubes de projeção } \\
\text { nacional para se manter. Isso é demonstrado em depoimentos que } \\
\text { apontam o futebol local como inapto para justificar o uso dos novos } \\
\text { estádios. }\end{array}$ \\
\hline E17 & $\begin{array}{l}\text { A audiência para o } \\
\text { futebol local não é } \\
\text { suficiente para manter a } \\
\text { arena }\end{array}$ & $\begin{array}{l}\text { Refere-se à falta de interesse dos torcedores pelos times locais, tanto } \\
\text { por estes não terem representatividade no cenário nacional quanto } \\
\text { por aqueles torcerem por times de outras localidades. Isso se } \\
\text { evidencia em relatos sobre a falta de tradição do futebol local, bem } \\
\text { como a grande incidência de moradores advindos de outras regiões. }\end{array}$ \\
\hline \multicolumn{3}{|r|}{ Encontrados apenas na posição da imprensa } \\
\hline E02 & utebol & $\begin{array}{l}\text { Indica a necessidade de uma condição financeira favorável dos } \\
\text { torcedores para que possam desfrutar dos jogos no novo estádio. Isso } \\
\text { é evidenciado pela indicação de que os elevados custos de } \\
\text { manutenção da arena repercutem no preço dos ingressos. }\end{array}$ \\
\hline E03 & $\begin{array}{l}\text { A Copa é parâmetro para } \\
\text { se pensar o modelo do } \\
\text { futebol local }\end{array}$ & $\begin{array}{l}\text { Refere-se à realização da discrepância entre a formatação do futebol } \\
\text { local como produto em relação ao que se viu na Copa do Mundo. Isso } \\
\text { é evidenciado por relatos de expectativa de que a oferta do futebol } \\
\text { local passe a emular o padrão daquele visto no evento e compatível } \\
\text { com as competições internacionais. }\end{array}$ \\
\hline E10 & $\begin{array}{l}\text { A Copa deveria servir } \\
\text { para modernizar a cidade }\end{array}$ & $\begin{array}{l}\text { Refere-se à expectativa de que sediar a Copa serviria como impulso } \\
\text { na modernização das cidades. Isso se evidencia em depoimentos } \\
\text { acerca de como os projetos de infraestrutura relacionados à Copa } \\
\text { eram vistos como um meio de elevar o estatuto da cidade. }\end{array}$ \\
\hline
\end{tabular}

Fonte: elaborado pelos autores.

No Quadro 2 apresentamos as funções enunciativas. Estas se constituem por orações iniciadas por um verbo no infinitivo, para destacar que tratam de uma ação dos enunciados com os quais se relacionam. 
Quadro 2 - Funções enunciativas

\begin{tabular}{|ll|l|}
\hline \multicolumn{2}{|c|}{ Funções } & \multicolumn{1}{c|}{ Descrições } \\
\hline F1 & Evidenciar um anseio pela modernização & $\begin{array}{l}\text { Demonstra a expectativa da população com relação à } \\
\text { possibilidade de desenvolvimento das cidades. }\end{array}$ \\
\hline F2 & $\begin{array}{l}\text { Indicar a existência de um padrão de } \\
\text { modernização }\end{array}$ & $\begin{array}{l}\text { Legitima um modelo de desenvolvimento a ser } \\
\text { alcançado pelas cidades. }\end{array}$ \\
\hline F3 & $\begin{array}{l}\text { Revelar um sentimento de inferioridade da } \\
\text { cidade }\end{array}$ & $\begin{array}{l}\text { Evidencia um reconhecimento de que as cidades se } \\
\text { encontram aquém da expectativa de sua população. }\end{array}$ \\
\hline F4 & Demonstrar implicações da Copa do Mundo & $\begin{array}{l}\text { Atribui à realização da Copa do Mundo mudanças às } \\
\text { cidades. }\end{array}$ \\
\hline F5 & $\begin{array}{l}\text { Denunciar artifícios na organização e nos } \\
\text { desdobramentos da Copa na cidade }\end{array}$ & $\begin{array}{l}\text { Indica ações políticas ou paliativas dos gestores para } \\
\text { legitimar a escolha das cidades-sede. }\end{array}$ \\
\hline
\end{tabular}

Fonte: elaborado pelos autores.

Por fim, as regras de formação estão dispostas no Quadro 3. Elas são apresentadas na forma de expressões com valor substantivo, no intuito de nomeá-las conceitualmente.

Quadro 3-Regras de formação

\begin{tabular}{|ll|l|}
\hline \multicolumn{2}{|c|}{ Regras de enunciação } & \multicolumn{1}{c|}{ Descrições } \\
\hline R1 $\quad \begin{array}{l}\text { Aspiração por um reconhecimento } \\
\text { de modernidade }\end{array}$ & $\begin{array}{l}\text { O sentimento de inferioridade das cidades leva ao desejo por } \\
\text { uma modernização, compreendida sob a ótica de um padrão } \\
\text { global estabelecido. }\end{array}$ \\
\hline R2 $\quad \begin{array}{l}\text { A Copa do Mundo como } \\
\text { encarnação do desenvolvimento }\end{array}$ & $\begin{array}{l}\text { A Copa do Mundo é vista como emblemática do paradigma de } \\
\text { desenvolvimento global que se almeja atingir. }\end{array}$ \\
\hline R3 $\quad \begin{array}{l}\text { A Copa do Mundo como } \\
\text { oportunidade }\end{array}$ & $\begin{array}{l}\text { Se reconhece na Copa do Mundo a oportunidade de inserção } \\
\text { numa lógica de desenvolvimento capaz de suplantar o } \\
\text { sentimento de inferioridade percebido nas cidades, mesmo } \\
\text { que, para isto, seja usado de artifícios em prol da imagem das } \\
\text { sedes. }\end{array}$ \\
\hline
\end{tabular}

Fonte: elaborado pelos autores.

\section{Apresentação da formação discursiva}

Denominamos a formação discursiva identificada de uma estética de desenvolvimento para a existência da cidade, uma vez que esta evidencia uma busca de se suplantar um sentido de atraso no processo de modernização, identificado numa lógica de desenvolvimento alicerçado na economia dos grandes centros e percebido como atingível por meio de um megaevento esportivo global (i.e., Copa do Mundo). Tal finalidade é almejada menos como uma necessidade de crescimento em si, mas como uma condição necessária de reconhecimento de um estado compatível com a imagem de modernidade do ponto de vista da cultura ocidental, fortemente alastrada na noção dominante de desenvolvimento econômico. Para tal, a premissa de parecer uma cidade desenvolvida supera a obrigação de sê-la, sendo a Copa do Mundo uma chance de se alçar a esta condição. Trata-se, portanto, de uma estética da existência 
almejada por essas cidades, com base numa lógica estilizada de desenvolvimento.

A Figura 1 apresenta as relações entre enunciados e os feixes de relações entre enunciados, funções enunciativas e regras de formação que culminaram com a formação discursiva. Foi sinalizada pelo uso de cores específicas a relação entre a ocorrência de cada um dos enunciados e as cidades em questão. Os elementos aparecem codificados de acordo com os quadros anteriores. A respeito das relações, indicamos por meio de setas aquelas de caráter incidental e por linhas aquelas de que compreendem relações síncronas, o que ocorre apenas entre enunciados.

Figura 1 - Mapa da formação discursiva

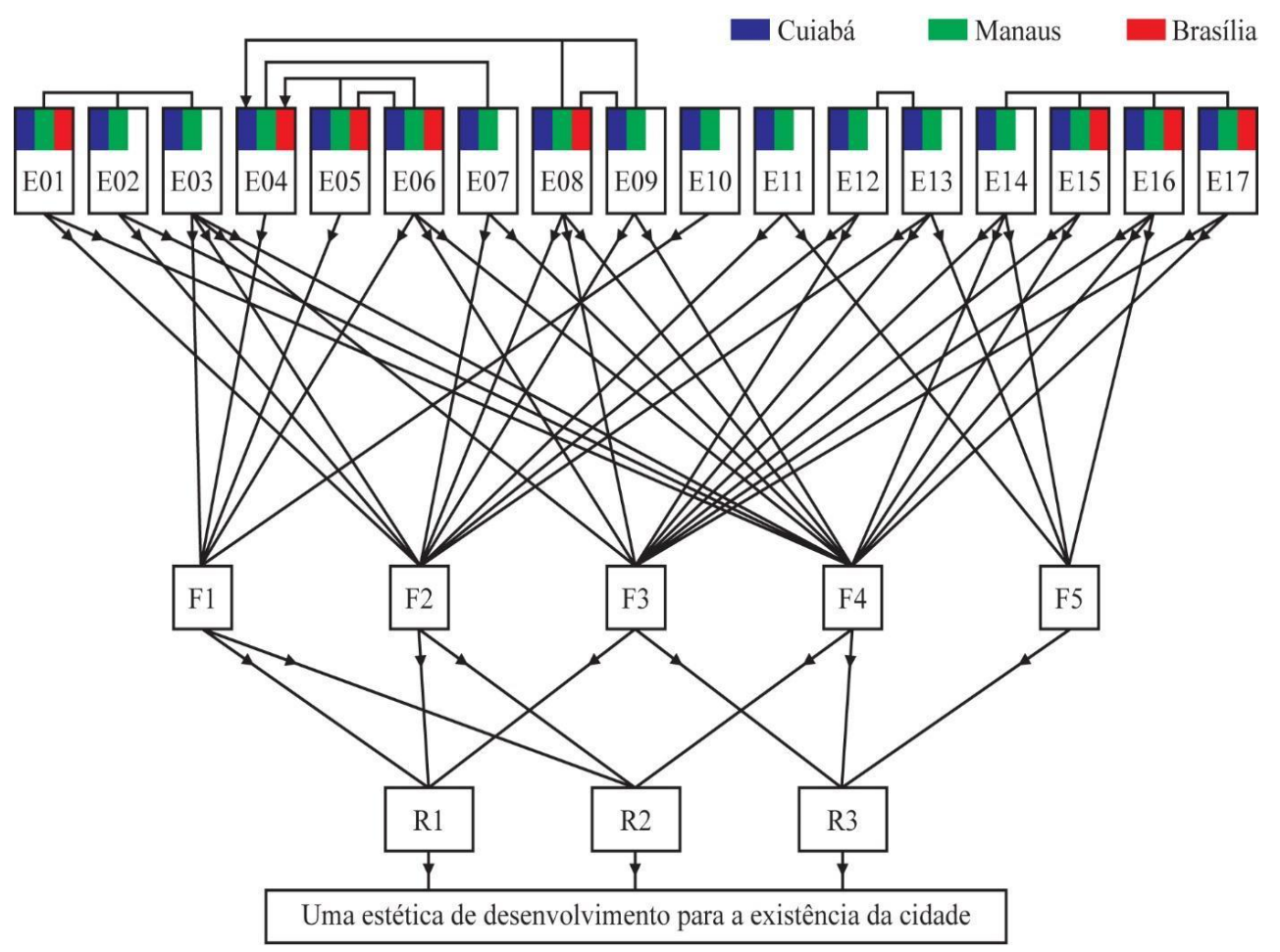

Fonte: elaborado pelos autores.

As relações entre os enunciados, bem como a forma como estes convergem para suas funções, apontam para grupos de significados particulares. Para ilustrar como nossa análise nos levou à identificação da formação discursiva, optamos por discutir os feixes de relações entre elementos a partir de tais grupos, debruçando-nos nos aspectos em que os mesmos demonstraram maior convergência e lançando mão de dados do arquivo, de forma que todas as funções enunciativas e regras de formação, bem como a maioria dos enunciados tenham sido ilustrados.

O primeiro grupo de enunciados relacionados entre si (E01 a E03) refere-se ao impacto que a Copa do Mundo causou na forma de pensar o futebol nas cidades. Os três enunciados estão relacionados ao entendimento de que exista um padrão de modernização (F2), assim como à demonstração das implicações da Copa do Mundo para as cidades-sede investigadas (F4). Conjuntamente, convergem para a concepção de como o mundial representa o desenvolvimento 
(R2). Esse feixe de relações pode ser ilustrado a partir de um trecho retirado de uma entrevista realizada com um jornalista de Manaus.

Aqui, depois da Copa, existe uma secretaria responsável pelos grandes eventos, e eles fizeram uma cartilha para os jogos na Arena da Amazônia. [...] Todo aquele caderno lá, de recomendações, era uma grande chance de profissionalizar o nosso futebol também. Aqui em Manaus mesmo, isso não funciona; todo mundo reclamando que esse negócio fica muito caro. Acho que esse negócio serviu só para trazer a Copa para a cidade mesmo.

A passagem descreve as mudanças organizadas e promovidas para o futebol local após a Copa (E01), bem como tais mudanças se apresentam como oportunidade para se modernizar o futebol local (E03). Por fim, conclui que, apesar da aparente projeção, os custos para esse progresso são elevados, reservados a poucos (E02). Tais aspectos apontam para implicações da realização da Copa do Mundo na cidade (F4), uma vez que os jogos realizados na arena modificaram a forma como o torcedor e a cidade vivenciam jogos de futebol, principalmente pela pompa e seriedade que transformou os jogos em eventos esportivos, repercutindo numa concepção de espetáculo futebolístico baseado no evento como um padrão desejável para o futebol local (F2). Esta lógica indica o entendimento de que ter sediado o evento na cidade conduza a uma oportunidade de desenvolvimento no que diz respeito ao futebol do estado (R2).

Um grupo mais extenso de enunciados relacionados ancora a associação entre o conceito de desenvolvimento e o sediamento da Copa com base no orgulho da população de contar com uma arena de padrão internacional em sua cidade (E04), o que, por sua vez, está relacionado à ideia de que o evento tenha propiciado desenvolvimento para as cidades-sede em estudo (E07). Isto é evidenciado em duas frentes. Na primeira, entre enunciados que indicam que o mundial proporcionou maior visibilidade e atratividade de turistas às cidades (E08 e E09). Tal qual o primeiro grupo, esses enunciados apontam para a repercussão do mundial na cidade (F4) e para um padrão de modernização (F2), aqui relacionado ao turismo (R2). Numa outra frente, o orgulho pela arena se evidencia na relação entre enunciados que dizem respeito à concepção de que o novo estádio contribui para inserir a cidade no cenário futebolístico nacional e para a atração de grandes eventos (E06 e E05). Essa relação converge para uma expectativa de modernização das cidades (F1), que aponta para uma pretensão de reconhecimento de desenvolvimento (R1) possibilitada pela Copa do Mundo (R2). Esse feixe de relações pode ser ilustrado a partir de um trecho retirado de uma entrevista realizada com um jornalista de Brasília.

Nós temos um estádio hoje que é para 72 mil pessoas e, obviamente, com um futebol que nós temos em Brasília, que não tem hoje nem um time na última série, que é a $D$, é um estádio fadado a ser um elefante branco, né? Não tem nenhum jogo no Estado hoje que vai preencher a sua capacidade, é uma obra muito grande para um futebol completamente sem tradição. Mas surgiu um ramo novo para o estádio, que é trazer jogo dos times de fora e isso tem salvado um pouco esse caráter de elefante branco. Esses jogos têm ativado a economia, movimentado a cidade; [...] o pessoal tem elogiado bastante. 
jogos de grandes clubes do país (E05) e, desta forma, aparecer no cenário nacional do esporte (E06). Tal compreensão aponta para um desejo por modernização em um aspecto em que a cidade ainda não conseguiu se desenvolver: o esporte bretão (F1). O reconhecimento por isso (R1) teria sido oportunizado, ainda que por linhas tortas, à estratégia adotada para viabilizar o estádio após sua adequação ao mundial (R2).

De forma análoga, mas remetendo a um sentido oposto, apresenta-se um dos enunciados que não se encontra relacionado a nenhum outro e que remete a como o mundial da Fifa deveria ter servido para a modernização das sedes (E10), revelando um anseio nesta direção (F1), que remete a uma imagem almejada (R1) por meio da Copa do Mundo (R2). Esse feixe de relações pode ser ilustrado a partir de um trecho retirado de uma entrevista realizada com um jornalista de Cuiabá.

Agora, o grande problema, é que pra levar o torcedor pra arena aqui, em Cuiabá, é a locomoção da torcida, sabe? Hoje em dia o estádio não tem ônibus, só quando tem grande jogos aqui. Mas quem vai no jogo do dia a dia é o povão. Esse povão que sai de Pedra 90 não consegue chegar na arena; o povão que sai do CPA não vai pra arena porque não tem ônibus; o pessoal de Várzea Grande como é que chega na Arena Pantanal? Não tem transporte, [...] tem um ou outro ônibus que demora duas horas pra passar.

O depoimento revela uma expectativa de que o sediamento do mundial possibilitasse uma modernização da cidade (E10). Particularmente, um anseio de um sistema de transporte urbano mais adequado (F1), compatível com a construção da arena na cidade (R2), que a alçasse a um nível global desse sistema (R1).

Outros dois enunciados relacionados (E12 e E13) elucidam como Manaus e Cuiabá se reconhecem como opções inferiores a cidades candidatas não contempladas como sede do evento, principalmente pela falta de uma cultura futebolística. Tais aspectos indicam o reconhecimento de um padrão de modernização (F2) do qual tais cidades estariam aquém (F3) e convergem para uma expectativa de serem reconhecidas como integrantes desta categoria (R1).

Esse feixe de relações é evidenciado em entrevistas realizadas com dois jornalistas manauaras, com ênfases complementares. Um deles é taxativo ao afirmar que Belém teria sido uma opção mais adequada do que Manaus como sede nortista da Copa. O outro não afirma isto categoricamente, mas, ao analisar o futebol local e a destinação da Arena da Amazônia, reconhece a superioridade do futebol do estado vizinho, afirmando que os times de Manaus só conseguem atrair um maior público quando jogam com adversários belenenses. $\mathrm{O}$ primeiro deles, por sua vez, afirma que o amazonense gosta de futebol, mas que o principal problema é o amadorismo dos times locais, que precisariam de maiores investimentos, ainda que reconheça que isto não caiba ao estado. O segundo é categórico em afirmar que o patrocínio da iniciativa privada seria a única saída para os clubes do Amazonas se desenvolverem.

Os depoimentos sustentam que a escolha de Belém teria sido mais adequada do que a de Manaus em virtude de a capital paraense ter uma maior cultura futebolística e uma organização mais profissional do futebol (E13). Defendem que o que falta ao futebol amazonense é justamente um maior profissionalismo, 
argumento ancorado fortemente no entendimento de que poderia haver um maior investimento privado para tal finalidade (E12). Assim, apesar de reconhecerem a inferioridade do futebol de Manaus (F3), apontam para um patamar considerado mais desenvolvido (F2). O entendimento de que esta meta seja atingível indica uma pretensão de que a cidade venha a ser reconhecida neste nível (R1).

Por fim, quatro enunciados relacionados entre si (do E14 ao E17) demonstram problemas na destinação das arenas construídas para receber jogos do mundial, evidenciando implicações negativas por se ter sediado a Copa (F4), ancorada, no entanto, no sentimento de inferioridade das cidades (F3). Tais aspectos convergem para o entendimento de que o mundial represente uma oportunidade pensada como uma imagem a ser projetada ao invés de efetivamente aproveitada (R3).

Em entrevista realizada com um cidadão de Cuiabá, o mesmo argumenta que a Arena Pantanal não é devidamente utilizada (E15) porque o futebol local não é capaz de comportá-la (E14), em virtude dos cuiabanos não se interessarem pelos times da cidade por entendê-los como muito frágeis (E17), se motivando a frequentarem jogos apenas de times dos centros mais desenvolvidos quando mandam suas partidas na cidade (E16). Tais aspectos revelam o entendimento acerca da inferioridade do futebol da cidade (F3), apontando para a Arena Pantanal como um legado inócuo (F4). Ao fim, o entrevistado dá "graças a Deus" o fato da cidade não depender da Copa para nada, uma vez que detém uma economia impulsionada pelo agronegócio, o que evidencia que ter sediado a Copa se referiu a uma oportunidade apenas relacionada à projeção da cidade (R3).

Em direção semelhante encontra-se o segundo dos enunciados que não se relacionam com outros, relativo ao entendimento de que as cidades foram "camufladas" para receber o mundial (E11), aspecto que aponta para o reconhecimento de um modelo de modernização (F2) que, ao não ser atingido, é emulado de maneira artificial (F5), indicando, respectivamente, uma aspiração (R1) e a oportunização da Copa apenas como uma projeção (R3).

Um cidadão manauara entrevistado para a pesquisa afirmou que só os principais corredores e as regiões de acesso à Arena da Amazônia e pontos turísticos da cidade foram cuidados e, ainda assim, apenas às vésperas e durante o evento, de forma a causar boa impressão aos turistas, mas que não reconhece nenhuma benfeitoria permanente para a capital do Amazonas. Com isto, podemos identificar seu entendimento de que a cidade foi "maquiada" para receber os jogos do mundial (E11), por meio de um tratamento contingencial (F5), baseado numa imagem ideal de cidade (F2) que poderia ter sido perene (R1) a partir da oportunidade de sediar um evento de tamanha magnitude (R3).

\section{CONSIDERAÇÕES FINAIS}

Esmiuçados os discursos relativos à construção das arenas nas capitais Manaus, Cuiabá e Brasília, retomamos o questionamento que norteou o presente estudo à luz das lentes teóricas que emergiram com o avançar das nossas análises. Nesse sentido, passamos a refletir e esmiuçar os pontos centrais de 
nossos achados como meio de propiciar uma ponte para uma reflexão de retorno à base teórica adotada.

Em relação à destinação das arenas, fica evidente uma preocupação com a subutilização pós-copa, principalmente em virtude da fragilidade do futebol das cidades investigadas, mas também, no caso de Cuiabá e Manaus, no entendimento de que as cidades não tenham a capacidade de comportá-las, inclusive com o questionamento de se realmente deveriam ter sido escolhidas como sede. Refletindo sobre o futebol dessas localidades, fica evidente uma preocupação com a maneira como o esporte poderia ser melhor desenvolvido, o que não se evidencia, por sua vez, como uma preocupação em Brasília.

A diferença como as três cidades pesquisadas refletem sobre a destinação na arena e o futebol local é emblemática de como a lógica de desenvolvimento identificada se deixe transparecer. Por um lado, como um entendimento de superação de uma percepção de atraso e, por outro, como uma possibilidade de projeção das cidades, sendo que Brasília se inclui apenas neste último.

Do ponto de vista das posições discursivas consideradas, vemos uma confluência de todas elas em aspectos que apregoam um certo brio pelas cidades. As posições oficial e da sociedade, quando separadas, estão sempre acompanhadas da mídia. A primeira foca na contribuição da Copa para o desenvolvimento das cidades e suas populações. A segunda pode ser dividida em duas frentes: por um lado, nos aspectos que corroboram a exaltação das cidades; por outro, nos pontos de vista mais críticos dirigidos ao entendimento de certa inferioridade da cidade e de seu futebol, bem como da destinação da nova arena. Por fim, os enunciados evidenciados apenas na posição discursiva da mídia repercutem uma preocupação com o futebol e a perda de oportunidade de modernização das cidades.

A formação discursiva aponta para a aspiração por um modelo de desenvolvimento; essa concepção de desenvolvimento mostra-se atrelada a práticas de existência que se ancoram em um conjunto de saberes que reconhece e legitima o padrão de desenvolvimento das nações ocidentais consideradas desenvolvidas. Esse padrão, global e homogeneizante, evidencia-se nos discursos investigados muito mais como uma aparência que propriamente um estatuto. A Copa do Mundo Fifa 2014, por sua vez, mostra-se como a oportunidade de legitimar a aderência a essa lógica, mostrando-se por vezes até como uma necessária ruptura de paradigmas no próprio futebol.

Essa formação discursiva remete à busca de um estatuto adequado àquilo que se compreende como moderno, o que fica evidente tanto quando se reconhece uma condição atrasada da cidade, quanto quando se trata de uma imagem almejada de cidade. É importante destacar nesse sentido que Brasília, como Capital Federal, alinha-se apenas e esta última vertente, sendo a primeira verdadeira somente para Cuiabá e Manaus, capitais de estados localizados em regiões menos desenvolvidas e mais periféricas.

Tais ambições se apresentam como possíveis por meio de um evento incidental, como ocorre com a Copa do Mundo e que se deve ser aproveitado, mesmo que tais anseios se revelem mais especulações que uma estilização para a cidade propriamente dita, pois é capaz de remeter a uma imagem de desenvolvimento. Dessa forma, revela-se uma estética da existência que se aproxima do modelo de desenvolvimento estabelecido pelas nações ocidentais 
consideradas desenvolvidas e almejadas por aquelas consideradas subdesenvolvidas ou em desenvolvimento. Esse modelo mostra-se, nos discursos analisados, como uma alteridade à qual as cidades visam igualar-se. Nesse sentido, o futebol converte-se num espetáculo que possibilita o engrandecimento de cidades acanhadas por si mesmo ou pela pouca representatividade dos times locais no cenário brasileiro, mas que vislumbram uma oportunidade de inserir-se num mapa mais amplo de desenvolvimento.

Reconhecemos como uma limitação da pesquisa a restrição a três das dozes cidades-sede da Copa do Mundo no Brasil. É possível se especular que uma lógica estilizada de desenvolvimento esteja presente em outras cidades que sediaram jogos do mundial. Entretanto, tal limitação alinha-se a própria definição do escopo de investigação, motivado pelo entendimento amplamente difundido de que as arenas dessas cidades representem um grande potencial de subutilização, argumento central de nossa problemática.Além desta, entendemos como limitação a ausência de entrevistas com gestores públicos das cidades estudadas. Buscamos minimizar o problema com o recurso à produção jornalística, tanto local quanto nacional, que incluíssem seus depoimentos. Ao mesmo tempo, essas limitações podem ser entendidas como uma relevante oportunidade para futuras investigações, tendo em vista as implicações econômicas, sociais e políticas da realização da Copa do Mundo Fifa 2014 no Brasil.

\section{AGRADECIMENTO}

A realização deste trabalho só foi possível graças ao apoio do Conselho Nacional de Desenvolvimento Científico e Tecnológico (CNPq). 


\title{
Football for what? - World cup arenas as a post-developmentist aesthetics
}

\begin{abstract}
The construction of new arenas for the 2014 World Cup in Brazil raised many questions, especially in relation to those identified as potential "white elephants", as is the case of Mané Garrincha Stadium (Brasília), Arena Pantanal (Cuiabá) and Arena da Amazônia (Manaus). Based on this, we addressed the following investigative question: What arguments constitutes the discourses on the Manaus, Cuiaba and Brasília arenas? For this purpose, we had access three discursive positions (official, society and the media), through a Foucauldian Discourse Analysis of interviews and direct observation, made on site, as well as documentary data. We found on both the Foucauldian conception of aesthetics of existence and the Post-development Theory ways for the interpretation of the findings, which converged to a discursive formation that relates to a logic of development that seeks, before a growth in itself, an image of modernity compatible with a global parameter.
\end{abstract}

KEY WORDS:2014 Fifa World Cup; arenas; aesthetics of existence; Post-development Theory; Foucauldian Discourse Analysis. 


\section{REFERÊNCIAS}

AGÊNCIA ESTADO. Ministro do Esporte se exalta ao defender "elefantes brancos". Gazeta do Povo, Londrina, 16 maio 2013. Disponível em: <http://www.gazetadopovo.com.br/ copa2014/sedes/conteudo. phtml?id=1373275\&tit=Ministro-do-Esporte-seexalta-ao-defender -elefantes-brancos>. Acesso em: 15 jul. 2013.

ALMEIDA, B. S.; BOLSMANN, Chris; MARCHI Jr., Wanderley; SOUZA, Juliano de. Rationales, rhetoric and realities: FIFA's World Cup in South Africa 2010 and Brazil 2014. International Review for the Sociology of Sport, v. 50, n. 3, p. 265-282, 2015.

ANDREWS, N.; BAWA, S. A post-development hoax? (Re)-examining the past, present and future of development studies. Third world quarterly, v. 35, n. 6, p. 922-938, 2014.

BAUER, M.; AARTS, B. A construção do corpus: um princípio para a coleta de dados qualitativos. In: BAUER, M. W.; GASKELL, G. (eds.). Pesquisa qualitativa com texto, imagem e som: um manual prático. 13.ed. Petrópolis: Vozes, 2005, p.39-63.

BAWTREE, V.; RAHNEMA, M. (Eds.). The Post-Development Reader. London/New York: Zed Books, 1997.

BELMIRO, S. H.; CARVALHO, A. A Fortaleza da Copa do Mundo: o legado como ferramenta de legitimação do megaevento esportivo. Estudos em Jornalismo e Mídia, v. 11, n. 2, p. 390-401, 2014.

BRUNO, D. P.; GUERRINI, L. Cultura y posdesarrollo: enfoques, recorridos y desafíos de la comunicación para otros mundos posibles. Signo y Pensamiento, $v$. 30, n. 58, p. 128-141, 2011.

CUMMINGS, S. Resurfacing an aesthetics of existence as an alternative to business ethics. In: LINSTEAD, S.; HÖPFL, H. J. (Eds.). The aesthetics of organization. New York: Sage, 2000. p. 212-227.

DASKON, C.; McGREGOR, A. Cultural capital and sustainable livelihoods in Sri Lanka's rural villages: towards culturally aware development. The Journal of Development Studies, v. 48, n. 4, p. 549-563, 2012. 2010. 
DINERSTEIN, Ana C.; DENEULIN, Séverine. Hope movements: naming mobilization in a post-development world. Development and Change, v. 43, n. 2, p. 585-602, 2012.

ESCOBAR, Arturo. Encountering development: the making and unmaking of the Third World. Princeton: Princeton University Press, 1995.

ESCOBAR, Arturo. Latin America at a crossroads: alternative modernizations, post-neoliberalism, or post-development. Cultural Studies, v. 24, n. 1, p. 1-65, 2010.

ESTEVA, Gustavo. Regenerating people's space. Alternatives, v. 12, n. 1, p. 125152, 1987.

FERGUSON, James. The anti-politics machine: 'development', depoliticization and bureaucratic power in Lesotho. Cambridge: Cambridge University Press, 1990.

FERNANDES, Daniel H. A nova infraestrutura de arenas e a Copa de 2014: impulsionando a cadeia de entretenimento no Brasil. Cadernos FGV Projetos, v. 8 , n. 22, p. 62-67, 2013.

FERREIRA, V. S. Aesthetics of youth scenes from arts of resistance to arts of existence. Young, v. 24, n. 1, p. 66-81, 2016.

FOUCAULT, Michel. A arqueologia do saber. 8. Ed. Rio de Janeiro: Forense Universitária, 2014a.

FOUCAULT, M. História da sexualidade v. 2: o uso dos prazeres. São Paulo: Paz e Terra, 2014b.

FOUCAULT, M. Uma estética da existência. In: MOTTA, M. B (Org.). Ditos \& escritos, v. 5: ética, sexualidade, política. 2. ed. Rio de Janeiro: Forense Universitária, 2010, p. 288-293.

GALVÃO, B. A. A ética em Michel Foucault: do cuidado de si à estética da existência. Intuitio, v.7, n. 1, p. 157-168, 2014.

GONÇALVES, Glauco R. A lógica do "elefante branco": obsolescência programada do espaço na Copa de 2014. Ateliê Geográfico, v. 7, n. 3, p. 240-256, 2013. 
HORNER, Lindsey. K. Networking resources, owning productivity: a postdevelopment alternative in Mindanao?. Globalisation, Societies and Education, v. 11, n. 4, p. 538-559, 2013.

HUIJER, M. The aesthetics of existence in the work of Michel Foucault. Philosophy \& Social Criticism, v. 25, n. 2, p. 61-85, 1999.

JUSTEN, Carlos E.; MORETTO NETO, Luís. Gestões do desenvolvimento e desenvolvimentos da gestão: da unilateralidade reificada à dialogicidade da simbiose homem/natureza. Cadernos EBAPE.BR, v. 11, n. 2, p. 295-310, 2013.

KINGSTON, M. Subversive friendships: Foucault on homosexuality and social experimentation. Foucault Studies, v. 5, n. 7, p. 7-17, 2009.

KIPPLER, Caroline. Exploring post-development: politics, the state and emancipation. The question of alternatives. POLIS Journal, v. 3, n. 1, p. 1-38, 2010.

LANGONI, Carlos G. Combinando o talento dentro e fora do campo: transformações econômicas e mudanças estruturais no futebol. Cadernos FGV Projetos, v. 8, n. 22, p. 38-44, 2013.

LATOUCHE, Serge. Existirá uma vida após o desenvolvimento? Estudos de Sociologia, v. 2, n. 16, p. 217-230, 2014.

LATOUCHE, Serge. In the wake of the affluent society: Explorations in postdevelopment. London/New York: Zed Books, 1993.

LEÃO, André L. M. S.; MELLO, Sérgio C. B.; VIEIRA, Ricardo S. G. O papel da teoria no método de pesquisa em administração. Organizações em Contexto, v. 5, n. 10, p. 1-16, 2009.

LUMMIS, Douglas. The end of development. AMPO Japan-Asia Quarterly Review, v. 25, n. 3, p. 36-40, 1994.

MARQUES, Antônio T. Qual será o legado da Copa do Mundo de Futebol de 2014 para o Brasil? Revista USP, n. 99, p. 57-66, 2013.

MENDONÇA. Renata. Copa: Prejuízo de 'elefantes brancos' já supera $R \$ 10$ milhões. BBC Brasil, 19 fev. 2015. Disponível em: 
MISKOLCI, R. Corpos elétricos: do assujeitamento à estética da existência. Estudos Feministas, v. 14, n. 3, p. 681-693, 2006.

MURRAY, S. Locating aesthetics: sexing the fat woman. Social Semiotics, v. 14, n. 3, p. 237-247, 2008.

PAIVA Jr.; Fernando G.; LEÃO, André L. M. S.; MELLO, Sérgio C. B. Validade e confiabilidade na pesquisa qualitativa em Administração. Revista de Ciências da Administração, v. 13, n. 31, p. 190-209, 2011.

PIETERSE, Jan N. After post-development. Third World Quarterly, v. 21, n. 2, p. 175-191, 2000.

POGODDA, Sandra. As culturas de desenvolvimento e o local em Timor-Leste. Revista Crítica de Ciências Sociais, v. 104, n. 2, p. 151-174, 2014.

RADOMSKY, Guilherme F. W. Desenvolvimento, pós-estruturalismo e pósdesenvolvimento: a crítica da modernidade e a emergência de "modernidades" alternativas. Revista Brasileira de Ciências Sociais, v. 26, n. 75, p. 149-162, 2011.

RADOMSKY, Guilherme F. W. Pós-desenvolvimento, indicadores e culturas de auditoria: reflexões críticas sobre governança e desenvolvimento. Ciências Sociais Unisinos, v. 49, n. 2, p. 155-163, 2013.

REVEL, J. Michel Foucault: conceitos essenciais. São Carlos: Claraluz, 2005.

RIST, Gilbert. The history of development: From western origins to global faith. London/New York: Zed Books, 1997.

SACHS, Wolfgang. The development dictionary: a guide to knowledge as power. 2 . ed. London/New York: Zed Books, 1992.

SEGALLA, V. Arenas Pantanal, Amazônia e Mané Garrincha dão R\$ 18 milhões de prejuízo. Repórter MT, Cuiabá, 23 dez. 2015. Disponível em: http://www.reportermt.com.br/geral/arenas-pantanal-amazonia-e-maregarrincha-dao-r-18-milhoes-de-prejuizo/51400. Acesso em: 05 jul. 2016.

SOUTO, Luiz; TORRES, Rodolfo. Arenas da Copa 2014: o desafio da viabilidade dos investimentos. Cadernos FGV Projetos, v. 5, n. 13, p. 44-52, 2010. 
TERRA. Arenas da Copa dão prejuízo de quase 18 milhões. Terra, 25 dez. 2015. Disponível em: https://esportes.terra.com.br/lance/arenas-em-brasilia-cuiaba-emanaus-dao-prejuizo-de-quase-r-18-

milhoes, db5a06a6ccff5d2f53c40f28cc07cba75t0vdifd.html. Acesso em: 05 jul. 2016.

Recebido: 02 out. 2017.

Aprovado: $19 \mathrm{dez} .2017$

DOI: $10.3895 /$ rbpd.v7n1.7088

Como citar: LEÃO, A. L.M. S.; FERREIRA, B. R. T.; CAMARGO, T. I.; MOURA, B. M.; FRANCO, S. M.

Futebol para quê? - Arenas da copa como uma estética pós-desenvolmentista. R. bras. Planej.

Desenv.,Curitiba, v. 7, n. 1, p. 104-127, jan./abr. 2018.Disponível em: <https://periodicos.utfpr.edu.br/rbpd>

Acesso em: XXX.

Correspondência:

André Luiz Maranhão de Souza Leão

Av. Prof. Moraes Rego, 1235 - Cidade Universitária, Recife - PE

Direito autoral: Este artigo está licenciado sob os termos da Licença CreativeCommons-Atribuição 4.0 Internacional. 